\title{
Designing and Enacting Weekly Micro-reflections as a Means of Professional Development of Early Career Educators: Voices from the Field
}

Ms. Taryn Shalini Bipat, University of Washington

Miss Yuliana Flores, University of Washington

Dr. Jennifer A. Turns, University of Washington

Jennifer Turns is a Professor in the Department of Human Centered Design \& Engineering at the University of Washington. She is interested in all aspects of engineering education, including how to support engineering students in reflecting on experience, how to help engineering educators make effective teaching decisions, and the application of ideas from complexity science to the challenges of engineering education.

Mr. Mitchell Fajardo 


\section{Designing and enacting weekly micro-reflection activities}

as a means of professional development of early career educators:

Voices from the field

\section{Introduction}

This project is situated in the professional development challenge of helping practicing educators in higher education advance their teaching. Although teaching occupies a large percentage of time for those employed in higher education, it is rare that educators have continued access outside of their everyday professional practice to advance their teaching. As a result, we can wonder where educators advance their teaching, and further, how can educators engage in their everyday practice such that this practice itself has the potential to function as professional development.

In this work, we explore the possibility that helping students engage in reflection can function as an opportunity for educator professional development. In particular, we have been exploring the use of micro-reflection activities--activities of around five minutes that an educator assigns to students in order to induce or support their reflection. In this work, we build on a sense of reflection as time spent looking back, thinking about, and connecting forward. This broad definition presents a large potential space of reflection activities, which provides great opportunity for educators to identify possibilities, design their own opportunities, inject their personalities, and otherwise experiment in their practice. Further, because five minutes or less represents a small portion of instructional time, it is unlikely that something will go dramatically wrong, thereby reducing perceptions of risk. Finally, because micro-reflection activities do not require an educator to dramatically change core features of their pedagogy, the use of micro-reflection activities represents a space of experimentation.

With these issues in mind, we asked: under what circumstances and in what ways can engagement in micro-reflection activities during one's teaching contribute to advancing one's teaching? To explore this question, we (the co-authors of this paper) worked together. Three of the authors, educators with different levels of teaching expertise, engaged in adding micro-reflection activities to weekly 2-hour classroom sessions. This was done with the support of the fourth co-author.

\section{Prior Work}

\section{Educator professional development}

In the context of teaching, professional development can be understood as intentional, structured experiences whereby educators have the opportunity to gain relevant knowledge and move toward new teaching practices. The goal is to increase the effectiveness of educational efforts in terms of student learning as well as other educational outcomes (such as equity). 
In a recent review of professional development endeavors, Darling Hammond, Hyler and Gardner (2017) identified seven features of effective professional development: content focused, active learning, collaboration, use of models and modeling, coaching and expert support, feedback and reflection, and sustained duration. In their work, Hill, Beisiegel and Jacob (2013) explore the limited guidance that some formal studies of professional development efforts have generated, and explore new approaches to studying professional development efforts. Analyses such as these point to the types of open questions surrounding what works in professional development.

Some of the open questions seem to stem from what is addressed in the professional development. For example, Korthagen (2017) reviews research on teacher professional development, and uses observations about trends in recent findings to argue that teacher learning is multidimensional, that teacher knowledge involves cognitive, emotional, and motivational dimensions, and that "connection with the person of the teacher is critical" (Korthagen, 2017, p. 387). Core notions of teachers needing knowledge of content and pedagogy, notions that had already been updated with the recognition of pedagogical content knowledge (Gess-Newsome, 1999), are increasingly being extended to include notions such as teacher identity (Beauchamp and Thomas, 2009) and authenticity in teaching (Kreber et al., 2007).

In higher education, the situation can be particularly challenging. Unlike the K-12 context, in which teachers are required to participate in professional development, educators in higher education can be called upon to teach with little prior or formal training.

\section{$\underline{\text { Reflection activities in higher/engineering education }}$}

There is a trend toward more focus on reflection in engineering education (Sepp et al., 2015). This is not surprising given the various educational links for reflection. Reflection, as a form of thinking that involves "stepping out and thinking about" is a way to learn from experience, a strategy associated with professional practice, an element of self-directed learning, and a key to transformative learning.

Recent research by the Consortium to Promote Reflection in Engineering Education (CPREE) has brought to light the range of reflection activities already being used by engineering educators and some of the dimensions along which the activities vary (Turns et al., 2017). In addition to documenting the space of reflection activities, the researchers associated with CPREE also reported on how engaging in conversations about student reflection functioned to support educator reflection (Turns et al., 2017). So, if talking about student reflection supported educator reflection (and thus contributed to professional development), what happens when educators engage in supporting student reflection? A starting point is to focus on engagement with activities of short duration in order to make the question feasible.

\section{Approach}

In this work we ask: under what circumstances and in what ways can engaging students in micro-reflection activities function as a site for professional development? Specifically, we 
wonder for a specific set of educators in a specific situation, (a) what micro-reflections are taken up?, (b) in what ways does the experience advance their teaching knowledge?, and (c) what features of the situation emerge as significant for appreciating the micro-reflections used and the advancement of teaching knowledge identified?

We explored these questions with an approach that combined three ways of knowing:

- a proof-of-concept mentality (a focus on exploring potentials and informing future iterations),

- both a descriptive and a reflective orientation (we sought to describe events and to document how the events were experienced), and

- an evolutionary perspective (in which we recognized that designs represent starting conditions that evolve over time in ways that are important to trace).

The focus of the work is on the efforts of three educators who integrated micro-reflection activities into their weekly teaching responsibilities (specifically the teaching of studio sessions). The three educators varied in their preparation for their teaching responsibilities in the course. One of the three educators was experienced in that she had taught in the course for over a year and had contributed to the redesigning several elements of the course itself. The other two educators could be considered novice in that this project was part of their first formal teaching experience. Of these other educators, one was an industry practitioner in the same discipline as the class and was currently enrolled in a professional masters degree in order to advance his disciplinary preparation. The other educator was a recent graduate of the undergraduate program in which the class was situated, had herself taken the course as an undergraduate, and was concurrently enrolled in a graduate program in education.

These educators were responsible for running two-hour studio sessions during each week of the ten week academic term. These studio sessions are run using preexisting teaching materials; and all studio sessions are run in an identical manner. The micro-reflection activities, however, were up to the educators. As a result, the educators had 10 opportunities to identify, design, and enact the micro-reflection activities. During the academic term, the educators were offered opportunities to discuss their micro-reflection activities with the lead instructor, but were not required to do so. In addition, the educators were given an opportunity to share what they had done during a weekly coordination meeting. At the end of the term, each of the educators created a list of the activities that they had done. In addition, to explore the ways in which the experience of using micro-reflection activities in teaching supported the educators in advancing their teaching knowledge, each educator engaged in personal reflection. As a team, we reviewed and discussed the personal reflection and collectively decided what to include in this paper. The first author was responsible for crafting text that offers a synthesis, while each of the other authors worked on first person accounts that bring their experiences directly into the manuscript. The first person accounts are formatted using italics in order to help the reader navigate the paper.

\section{Results 1 - Activities}

In this study, a total of 30 micro-reflection activities were used. These activities included: turning questions into snowballs, comparing before-and-after understandings on index cards, 
performing skits of memorable moments, and crowd-sourcing visualizations of students' level of understanding. Selected activities from each of the educators are included in Tables 1 to 3 below. These activities varied by materials used, by social engagements, and by purposes (e.g. assessing student learning, supporting student learning, or simply having fun). In addition, some activities created information that was processed after the activity (such as some of activities that involved students sharing information on notecards) while other activities were primarily in the moment (such as embodied activities).

One note is that none of the educators include the activities done on week 4 or week 7 . A micro-reflection activity was already present in the instructional materials for those weeks, and the educators collectively decided to use the already designed activity. Interestly, the activity did not go as well as the activities the educators had designed themselves.

In the rest of this section, the educators discuss their activities, the thinking behind their activities, and observations concerning the outcomes. (Note: the educators are identified by pseudonyms for this draft manuscript. In the final manuscript, the names will be those of the authors).

Taryn. In designing my activities, I wanted to show my students how approachable and fun I can be as a teacher, part of this is also showing them that HCDE as a topic is exciting, novel and creative in the way we think. For these reasons, I decided that I was going to take the leap of faith and try to make each reflection engaging through embodiment. By embodiment, I mean that the students could get up and use their bodies and movement to reflect on what they did during the class.

As I did each activity, I tried to expand their idea of how they could use a reflection and also at the same time try to connect it to the user centered design topic of the week. It helped that I already knew what was going to come every week and even what type of mood the students would be in. So for more high energy weeks, I had a more lowkey activity and vice versa.

Overall the activities went well, students were engaged and had fun, and it was a lighthearted way to end the class. For example with the skits, it was one of the final moments of class so they actually got to think about everything they had done for the quarter and at the same time they were able to have a couple of last laughs with their classmates. However, I did realize at the beginning of the quarter how disconnected the activities were from the content they learned in class. Additionally, while embodiment was fun, students spent too much time playing around and it never seemed like they were actually trying to reflect critically. At the same time, since this was a 5 minute reflection, I had a lot of questions but mostly how deep do we want students to think in such a short time span?

Table 1. Selected activities used by Taryn

Week 1 I had the questions about their experiences placed all across the room on the whiteboards. Then students got up and answered any one of the questions then we went over them in class and tied tht to what they would be working on for the rest of the quarter. 


\begin{tabular}{|l|l|}
\hline Week 2 & $\begin{array}{l}\text { Snowball Reflection - Students had to write something down on the paper that they } \\
\text { wanted to take away for the day, then they throw it at each other and someone } \\
\text { random will collect the reflection. }\end{array}$ \\
\hline Week 6 & $\begin{array}{l}\text { Students had to write one question that they had on a piece of paper and then we } \\
\text { passed it around the room. They then had to find the person with their paper and } \\
\text { discuss what they think the answer was. We went over a couple of the questions. }\end{array}$ \\
\hline Week 8 & $\begin{array}{l}\text { I asked my students to write their thoughts on index cards. On one side they had to } \\
\text { write one take away they had for the quarter and the other side they had to write one } \\
\text { question they have that they would like to be answered. it could be about HCDE, } \\
\text { HCDE } 210 \text { or anything they might want to know about HCDE } 210 .\end{array}$ \\
\hline Week 9 & $\begin{array}{l}\text { I asked students to create a physical prototype with their group (it could be absolutely } \\
\text { anything but it had to be fun). Then they had to reflect on ways that they might create } \\
\text { this same prototype using other materials. }\end{array}$ \\
\hline Week 10 & $\begin{array}{l}\text { I asked students to do skit of their most favorite moment this quarter. It could be } \\
\text { whatever they wanted it to be but they had to think about that experiment and try to } \\
\text { recreate it with their group. They then performed it and the class had to think about it } \\
\text { and try to guess what it was. }\end{array}$
\end{tabular}

Taryn focused on embodiment to get students moving around and reflecting, simultaneous. Meanwhile, Mitchell was motivated to use their personal experiences with photography to engage students in reflections.

Mitchell. Initially, I thought that I might use the same reflection activity (the photo activity described in the first row of Table 2) for the duration of the quarter, such that the email responses could be assembled and reviewed holistically as a reflective journal of sorts. I was also curious to see what students would photograph as representations of their experiences. Students seemed to enjoy the activity, and some of the students engaged with each other to be part of each other's photos (e.g. a team photo). The written captions were mostly simple (as expected). Some of the engagement seemed to stem from novelty, so I was hesitant about repeating the activity.

I did the activity in the second week because I wanted to get a better impression of how the "photo pseudo-journal" might engage students if it was a recurring activity. I was hoping the written portion of the prompt would help students recognize their growth, since the IxD sprint has several similar qualities to the UCD charrette. While the students didn't necessarily seem disengaged with the activity, I did end up deciding to use different activities in the future weeks to pursue more novelty in the micro-reflections.

During weeks 5, 6, and 8, I designed activities that leveraged the practices students were studying in the class. For example, in week 5, my intention was that this reflection could serve as extra sketching practice while also encouraging students to consider reflecting on potential strategies (or at least things to consider). In addition, this seemed like a nice break from the more verbal reflections of the previous weeks. I saw a handful of delighted/amused responses from the students when I revealed the prompt. While there weren't very many responses that showed students using the ideation strategies (side note: I might push this a bit harder in the future), this was probably among my favorite of my micro-reflection activities. In week $8, I$ 
wanted students to look forward and anticipate what features the deliverable they ought to be mindful of. As expected, students' responses to the graphs would suggest an increase in understanding in InfoViz and Tableau (though the question was biased in the first place, so perhaps the exact prompt should be reconsidered). In regard to anticipating challenges, surprisingly few students expected to have trouble with Tableau itself and anticipated that considering specific user groups and research questions would be the hardest part. This was another favorite micro-reflection of mine, though as stated, I might want to change the prompt to include less bias and provide something more informative.

I found the activity in week 6 needed work. It was meant to serve as additional "reflexivity" practice. To paraphrase, most of the responses were along the lines of "today's weather bums me out/reduces my energy." I wonder how much of this was genuine, and how much of this might have been caused by a self-fulfilling prophecy effect, in which I anticipated that students would be distressed by the weather and the students simply responded to my expectations.

I ended in week 10 with a fairly holistic micro-reflection. If there had been time to share, it would have been interesting to see what students would have wanted their past selves to know (and it might have informed what we as instructors might do to prepare future students from the start.) Because I didn't collect the index cards, I wasn't able to get a sense of what students wrote.

Table 2. Activities used by Mitchell

Week 1 Students were asked to take a photograph of something that they felt represented their experience in the day's studio and write (as a caption of sorts) a response to one of the reflection questions (e.g. what surprised you? what did you most enjoy? what was difficult?). They emailed their responses to me.

Week 2 Once again, students were asked to take a photograph and write a caption (though this time, the prompt asked them what they felt more confident in between the previous week and this one).

Week 5 Students were asked to "sketch [themselves] sketching ideas." Students were encouraged to consider ideation strategies (but weren't required to do so).

Week 6 Students were asked to consider how today's weather might affect the way they think and feel, and how they might respond to account for this effect. (Note: The weather was gray and a little rainy, at least in my morning session.) Answers were written on index cards.

Week 8 Students were asked to (1) "plot" themselves on a graph on the whiteboard showing their understanding of InfoViz and Tableau at the beginning and end of class and (2) indicate which portions of the deliverable they expected to be the hardest and easiest. (Students used sticky notes to do this)

Week 10 Didn't have much time for a micro-reflection, but I briefly asked students to write their past selves a note (on an index card) describing what they would want themselves to know about the course (e.g. things to expect, tips to succeed, challenges to prepare for, etc.). (I did not collect the index cards at the end) 
Mitchell' reflection activities transitioned from personal engagement of the educator in the form of photographs to focusing on the class deliverables. Yuliana used physical artifacts for her reflections to come to a deeper understanding of how students were feeling in class.

Yuliana. While I was designing my mini-reflections, I remember trying to empathise with my students' feeling of not knowing what to write or what counts as a "good" reflection. For this reason, I was intentional in using index cards as the material for all my mini-reflections as well as being mindful of the prompts and time. My intention was that the index cards' small space would make the reflection activities appear as low-stakes resulting in higher student participation. In addition, I was paying attention to how to phrase the request, because I recognized that saying "what is a purpose..." (as opposed to "what is the purpose...") alleviates pressure from students thinking there is one right answer.

Over time, I started to pay attention to different things, and the purpose behind my activities changed. At the beginning, my goal for the mini-reflections was to have students reflect on what they were learning in studio and how that connected to their passions. However, as a new educator I became aware of some of my students disengagement which impacted my reflections to be more focused on their experience in studio or how they were feeling.

In the end, students always participated and engaged in the activities. Students specifically seemed to have enjoyed the activities that were focused on their feelings. An example would be the activity from week 6 which asked the students to draw a pumpkin with the facial expression that mirrored their current mood. I provided them one minute to draw and then had them share with their table. There was one particular group who all laughed when they shared their drawing because they all had drawn a variation of sleepy. After having had a handful of reflections be centered around understanding my students' experience I become confident in myself as an educator, but began to wonder if I had done a disservice to my students by not having them reflect on their knowledge/understanding of the material.

Table 3. Activities used by Yuliana

Week 1 I had my students complete a highlighted index card reflection. Each highlighted card had the students reflect on different things (green - questions, orange - surprise, pink enjoy/valued, and yellow- bonus) and 30 seconds was given to complete each card.

Week 2 I had my students draw a line in the middle of the index card. I first prompted the students to bullet words that came to mind when they thought about IxD. Afterwards, I asked them to take a moment to look at the list and then, on the right of the card, they had to create a sentence that summarized their understanding of IxD. Took about $3.5 \mathrm{~min}$.

Week 3 Thorns and Roses (challenges \& good). I was interested in learning what the students enjoyed doing and what could be better explained in the future/avoided.

Week 5 I had the students complete the analogy "this class today feels like it's _. . I was getting a bit nervous with some of my students engagement so that purpose of this reflection was to understand how the students were feeling especially when coming into class. 


\begin{tabular}{|l|l|}
\hline Week 6 & $\begin{array}{l}\text { I had the students draw a pumpkin with a facial expression that reflected how they } \\
\text { felt on an index card. At this point I was concerned with how my students were } \\
\text { feeling in studio. My hope was for this activity to let me know how my students were } \\
\text { feeling. }\end{array}$ \\
\hline Week 9 & $\begin{array}{l}\text { I asked the students to write on an index card what they found the most surprising } \\
\text { about physical prototyping/LittleBits (a resource used in the studio). }\end{array}$ \\
\hline
\end{tabular}

\section{Results 2 - Advancement of teaching knowledge}

In order to claim that something functions as professional development, it is necessary to demonstrate that those who participate advance their teaching knowledge. In the related work section of this paper, we touched on the various kinds of knowledge that might be involved including traditionally accountable knowledge such as knowledge of content, pedagogy, and students. In addition, we touched on the increasing attention being given to issues such as teacher identity and teacher authenticity. In our project, we saw evidence of these kinds of knowledge. In particular, the first person accounts in this section include

- pedagogical insights related to instructional planning (such as the difficulty of planning and getting calibrated to what can be done in a specific period of time), adapting activities from another context to one's own, and the importance of good instructions;

- student-based insights such as how students react in different circumstances;

- personal insights such as growth in confidence as a teacher and a growing awareness of how to work toward aspirational goals in higher education while being pragmatic; and - future-oriented insights such as setting goals for designing new activities.

Now we turn to personal voices of each of the three educators where they highlight specific elements of their individual experiences. In this first account, Taryn situates her insights in her prior experience with the course.

Taryn. Being knowledgeable in how each course is run, helped me figure out what types of reflections needed to be created. Through my first quarters teaching this class, there has always been a playful and creative side to HCDE 210, which allows for the development of wild ideas. This helped me better understand what types of reflections to design and the primary reason for choosing embodiment as my primary constraint. It is actually crazy to see how much can be done in 5 minutes. Our studios are already designed at an extremely fast pace but usually we are just scratching the surface of what It means to be a user centered designer, however, I soon learned that 5 minutes was not really enough time for us to get into the types of reflections I wanted to achieve. Part of this problem is that I had to define reflection for the students and I had a strong idea that reflections are a device that can help us think thoroughly through what we have done to help make us better and more responsible designers.

I did start off the quarter by teaching my students what it meant to reflect and why it is so important to the design process. This helped a lot when trying to achieve the most out of the 5 minutes. However, I tried to be too innovative and almost took too many risks when planning. I used a lot of online resources to figure out how to get students moving around. Even though I do have a lot of HCDE time, I think there was also room to try out techniques so I usually tried to combine multiple types of reflection activities that have been used by other educators out there. 
While these online resources are helpful, they do not seem to actually help cater to my students. Our teaching situation is pretty unique and now I've learned that it requires an additional step of preparedness. I want to still try these embodiment activities in the future but now I need to prepare them all together so that they can build off of each other while still be tied to each studio. Additionally, as the quarter picked up, I started to lose momentum so designing them as a whole can try to keep the motivations high.

Unlike Taryn, Mitchell used these micro-reflections as an opportunity for professional development. Throughout the process, Mitchell realized that adding novelty to his reflections was difficult but similarly to Taryn quickly realized that additional preparation could lead to stronger student engagement.

Mitchell. I recall being a little nervous to plan my own activities, trying to make them engaging but also interesting to me and useful to the students. With the exception of my initial micro-reflections and the mix \& match cards, I tried to make each activity relevant to the weekly sprint topic. Some weeks when I was busy it was hard to make time to plan a good activity on advance. I recall piloting my first micro-reflection with Jennifer and Wendy which helped a lot. I didn't pilot the others in advance, often because I hadn't planned then until the night before (or occasionally the morning of) studio.

Seeing the students light up with delight and amusement was a treat during the weeks when I had more interesting micro-reflections. My favorites were my photo reflection on week 1 , the ideation sketching, and the information visualization ones. It was also satisfying when they incorporated concepts from class into their responses, which gave me feedback about what they were successfully learning.

One takeaway for me was that it is very easy to fall back on verbal (written or spoken) reflections, but the micro-reflections with more novel elements (sketching, photographing, plotting on a graph with sticky notes) were typically more engaging. That said, planning a novel reflection activity takes more than a bit of thought and planning, which I didn't always have, in which case I would fall back on standard written reflections. Piloting the activities is always a plus.

Interestingly, one of my prevalent assumptions was that students would be hard to please with a micro-reflection activity. I was concerned about the risk of them becoming disengaged and thinking the activity was a waste of time. I think if I challenged this assumption and supposed that the majority of students are more willing than I expect to approach the activities without judging them, perhaps it might actually be easier to include novel elements. I might also remove the self-imposed constraint that the micro-reflection should be relevant to the weekly sprint, potentially reducing the burden of coming up with new activities.

Connecting to my disciplinary work, if I view them from the lens of my development as a designer, then the micro-reflections feel more like designed experiences. The students of course are the users, and I become more focused on their delight and satisfaction with the experience. But the instructor is also a user, and I think about the experience if coming up with reflections and implementing them (and also getting feedback on how they go).

As I look ahead, I'm thinking that novelty and (potentially) relevance are salient factors to consider when designing reflection activities. Increasing the ways in which reflection can occur can support spontaneous/self-directed reflection in the future. Additionally, it's important to consider not only the existence of reflection practices but to support the creation of new ones, 
since as an instructor, it's engaging and satisfying to make your own. Also, I want to engage in spontaneous novel reflection of my own more often, but also practice mindfulness in determining the roots of my thoughts and experiences.

In this third account, Yuliana highlights her evolving confidence in herself as an educator. Unlike Taryn and Mitchell, this is Yuliana's initial experience designing activities for students. The experience of designing and enacting micro-reflection activities was a chance to calibrate her own ideas about reflection in relation to her expectations of students.

Yuliana. The work with the micro-reflection activities involved a wide range of emotions and insights. In the beginning it was often uncomfortable to think about what type of reflection I wanted to have my students do, how I was going to execute the activity, and what I was going to have the students reflect on. Furthermore, I was scared that students would not participate. This fear subsided by the third week but it was replaced by the fear of discovering how the students felt about my teaching or the studio. I began to enjoy the reflections when I noticed they were being well received by the students. Reflections were also moments of surprise especially when students themselves were surprised when discovering they were not the only ones feeling a certain way.

In terms of insights, I learned how hard it is to come up with reflections. It involves more than just thinking up prompts - you have to be very thoughtful of the wording and the time in which you present the reflection. You also have to think about how long it should be and the type of material you're going to use. In other words, there is quite a bit of planning and intentionality involved because it's challenging to know the impact you are trying to have on the students.

When I think through my reactions, I think I was uncomfortable writing reflections because I consider reflections as the moments where you really gain knowledge-you look back at how things went, what you learned and then connect it to the gaps in your current knowledge. This high regard for reflecting put pressure on me because I wanted students to really get a lot from these reflections. At the same time, as a new educator, I was a little skeptical with my own teaching style and I wanted to get more feedback on how to improve. So there was definitely some tension - wanting them to gain knowledge versus wanting to learn how I'm doing as an educator.

The work with the micro-reflections, alongside my other activities, helped me become aware of several assumptions. Such assumptions concerned my role as an educator and what it means to be a student in higher education. Once I was able to name my assumptions I realized that I need to be more carefree with reflections. Moving forward, I want to help my students tie what they learn in each section to their passions so that they can see each thing align with what they're interested in. My thoughts remain the same about reflections - they're valuable. I just need to be able to not hold reflections as some high thing - they should also be fun and allow students to be creative.

The three educators gained valuable insights from their micro-reflection activities to aid in advancing their teaching knowledge. All three, noted that designing micro-reflection activities means stepping out of their comfort zone, however by creating something novel and taking risks, there could be more benefit to the student. Taryn did this by including activities that involved student embodiment. Mitchell incorporated concepts from class as a way to measure student 
learning, and Yuliana talked about curating specifics related to time and wording around each of the micro-reflection activities.

Part of advancing teaching knowledge is further understanding students' needs. For all three teachers, they were able to gain some student-based insights. Taryn and Yuliana both learned that with a very specific time slot, students require a very curated process; each minute of a reflection should be well planned out. This leads to taking more time to specifically describe the purpose of the reflection activity. Furthermore, all the teachers noted that this was an opportunity to give students more amusement in class and get them more interested in their own passions and class topics.

As these educators try to assess how to improve in teaching, they have also gained valuable personal insights on their own pedagogical styles. Taryn realized that her teaching momentum declines over the quarter and so additional planning is required to increase overall motivation to keep students excited and engaged. For Mitchell, it was engaging and satisfying to bring his own experiences into these micro-reflection activities. Lastly, Yuliana was often uncomfortable to think about what type of reflection activities she wanted students to complete because of concerns that students might not participate and how they might react assuming they did participate. However, overtime these concerns dissipated.

With each teachers' new learnings come the potential to achieve future goals. Taryn feels that strong future directions are allocating more time to planning and finding ways to combine techniques from a variety of reflection activities. Mitchell notes that novelty and relevance are important to consider when designing micro-reflection activities in that this can help support spontaneous self-directed reflection in the future. Yuliana notes that in the future, she does not need to treat reflection activities so formally, there should be more room for flexibility and fun.

\section{Results 3 - How key features of the approach evolved}

In this section we explore how our understanding of key features of our approach evolved as they were socially constructed across the timeframe of the project. The social construction of these project features is significant to anyone interested in critically understanding what was behind the enactment and knowledge gain results presented in the previous sections.

Activities: Mighty micro. A key feature of this work is the notion of "micro" in the term micro-reflection activities. At the start, micro was operationalized as approximately five minutes. In our debriefing conversations, we noted how micro as five minutes in this context came to have specific significance. For example, micro as five minutes meant, in this context, five minutes of a 110 minute period. In other words, the micro-reflection activities occupied approximately 5\% of the instructional time. At the same time while the activity may have only required $5 \%$ of the time, it was observed that five minutes is actually a long time and that much can be done in five minutes. assuming one thinks carefully and strategically about what to do. Thus, the notion of micro may have served initially to reduce pressure but there was sufficient substance in a five minute period for there to be significance. 
Weekly: Productively repetitive. A second feature of this project was the repetition--the goal for the educators to incorporate a micro-reflection activity into each of the ten instructional sessions for which they were responsible. As it turned out, ten sessions created "wiggle room" in that it was possible to miss doing one or two activities without disrupting the overall effort. In addition, as was noted in the first results section, the goal of ten micro-reflection activities included two times when all three educators chose to try a reflection activity that was already incorporated into the instructions materials. These experiences of twice using an activity designed by someone else provided an interesting reference point for their own efforts, with their own efforts still being the core. Thus, we conclude that having the micro-reflection activities be a weekly effort created an amount of repetition that was demanding without being onerous and created space to occasionally not design while still having the overall focus being on design.

Meetings: Supportively collaborative. One feature of our project was discussion of the micro-reflection work during each weekly meeting. The three participating educators shared their experiences and their activities with each other. This public sharing was originally motivated by a data collection goal (i.e., capturing the activities being done, the goal of these activities, and the outcomes). In our debriefing, it was noted that the public sharing and associated conversations functioned to do more than simply create documentation. The public sharing also created opportunities for collaboration and mutual support: as a form of accountability, as a way to get feedback on personal ideas (another form of support), as a way to gain inspiration and new ideas, and as a way to maintain enthusiasm and motivation for continued work. In general, the public sharing helped to establish norms and create solid grounding. Over time, the public sharing became less frequent and a shorter duration. In a way, the early public aspect of the work was a form of scaffolding, and reducing the frequency and duration of public sharing was a means of removing the scaffolding. If others were to try a similar project, deciding how to support public sharing and how much public sharing to have would be important to consider.

\section{Concluding remarks}

In this work we asked: under what circumstances and in what ways can engaging students in micro-reflection activities function as a site for professional development? Specifically, we wonder for a specific set of educators in a specific situation, (a) what micro-reflections are taken up?, (b) in what ways does the experience advance their teaching knowledge?, and (c) what features of the situation emerge as significant for appreciating the micro-reflections used and the advancement of teaching knowledge identified? We situated this work amidst work on professional development as a problem space and work on supporting student reflection, and addressed these questions with a proof-of-concept mentality, a descriptive and a reflective orientation, and an evolutionary perspective.

Our analysis of the reflection activities enacted in this project showed that these activities had much variation--they varied by materials used, by social configurations (individual students, students in groups, etc), and by purposes (assessment of student learning, support student learning, have fun). The project had been partially motivated by a sense that the space of possibilities was large, and the variation in the reflection activities illustrated what this can mean. 
Such variation is key to imagining that a project like this could function in other domains and with other educators.

Our analysis of this effort as professional development focused on the types of knowledge gains or insights recognized by the individuals on our team. We identified pedagogical insights, student-based insights, personal insights, and future oriented insights. It is interesting to note the breadth in the insights and to wonder what frameworks for professional development /

advancement of teaching would could be used to help capture or organize this breadth for future projects. For example, we might playfully consider how the insights cut across Maslow's hierarchy of needs (to think about what counts as safe vs. risky in teaching alongside what self-actualization looks like for teachers) or more seriously explore the work of Dall-Alba and Sandberg (2006).

Our retrospective analysis of key features of our project provided a chance to highlight the particular significance of "micro" in our notion of micro-reflection activities, to highlight the value of repetition, and to examine the benefits of having work stay public. As such, future work should attend to these features.

We interpret our results as providing promising evidence that designing and enacting micro-reflection activities with students has the potential to function as a powerful form of professional development. Further, the details we have shared can be used by those interested in taking a next step. In addition, we readily note that our work was in a specific context (a class with a studio pedagogy). Perhaps additional work in more traditional pedagogical contexts could see the extent to which the use of micro-reflection activities works elsewhere.

Finally, for those readers interested in trying micro-reflection activities for any reason, we offer the following advice; (1) Planning is key. (2) It is important to start off this micro-reflections with explanation of what type of reflection this is, expectations and why we do reflections. (3) It is important to connect the reflection activities to the class content so it does not seem irrelevant. (4) As an educator, it is important to consider who your students are and how they interact with these micro-reflections--this might mean changing up your fixed plan along to way to get better engagement as the quarter goes along. (5) Don't be afraid to try something new! These micro-reflections are a source of novelty in a pretty fixed syllabus so it can be fun and creative.

\section{Bibliography}

Beauchamp, C., \& Thomas, L. (2009). Understanding teacher identity: An overview of issues in the literature and implications for teacher education. Cambridge journal of education, 39(2), 175-189.

Dall'Alba, G., \& Sandberg, J. (2006). Unveiling professional development: A critical review of stage models. Review of educational research, 76(3), 383-412.

Darling-Hammond, L., Hyler, M. E., \& Gardner, M. (2017). Effective teacher professional development. Palo Alto, CA: Learning Policy Institute.

Gess-Newsome, J. (1999). Pedagogical content knowledge: An introduction and orientation. In Examining pedagogical content knowledge (pp. 3-17). Springer, Dordrecht. 
Hill, H. C., Beisiegel, M., \& Jacob, R. (2013). Professional development research: Consensus, crossroads, and challenges. Educational researcher, 42(9), 476-487.

Korthagen, F. (2017). Inconvenient truths about teacher learning: towards professional development 3.0. Teachers and teaching, 23(4), 387-405.

Kreber, C., Klampfleitner, M., McCune, V., Bayne, S., \& Knottenbelt, M. (2007). What do you mean by "authentic"? A comparative review of the literature on conceptions of authenticity in teaching. Adult Education Quarterly, 58(1), 22-43.

Sepp, L. A., Orand, M., Turns, J. A., Thomas, L. D., Sattler, B., \& Atman, C. J. (2015). On an upward trend: Reflection in engineering education. In Proceedings of 2015 American Society of Engineering Education Annual Conference.

Turns, J. A., Scalone, G., Arif, A., Lovins, T., \& Atman, C. (2017, November). Dimensions in Designing Reflection Activities. In 2017 7th World Engineering Education Forum (WEEF) (pp. 120-125). IEEE.

Turns, J. A., Sattler, B., Thomas, L. D., Atman, C. J., Bankhead, R. B., Carberry, A. R., ... \& Yasuhara, K. (2015). Reflecting on reflection. In 2015 122nd ASEE Annual Conference and Exposition. American Society for Engineering Education. 